\title{
Possible delayed diagnosis and treatment of metastatic differentiated thyroid cancer by adopting the 2015 ATA guidelines
}

\author{
Domenico Albano', Francesco Bertagna², Mattia Bonacina', Rexhep Durmo', Elisabetta Cerudelli', \\ and Raffaele Giubbini ${ }^{2}$ \\ ${ }^{1}$ Nuclear Medicine, Spedali Civili Brescia, Brescia, Italy, ${ }^{2}$ Nuclear Medicine, University of Brescia and Spedali Civili \\ Brescia, Brescia, Italy, ${ }^{3}$ RCCS Istituto Ortopedico Galeazzi, Milan, Italy, ${ }^{4}$ Endocrine Unit, Azienda Socio-Sanitaria \\ Territoriale, Mantua, Italy, and ${ }^{5}$ Endocrinology, Vita-Salute San Raffaele University, Milan, Italy
} Maria Gazzilli', Maria Beatrice Panarotto', Anna Maria Formenti ${ }^{3}$, Gherardo Mazziotti ${ }^{4}$, Andrea Giustina ${ }^{5}$

Correspondence should be addressed to D Albano

Email

doalba87@libero.it

\begin{abstract}
Objective: According to the 2015 American Thyroid Association (ATA) guidelines, thyroid ablation by iodine-131 (I-131) therapy is absolutely recommended only in patients with high-risk differentiated thyroid cancer (DTC). Often distant metastases are not recognized early and they can stay silent for long time. The aim of our study was to retrospectively analyze the prevalence of metastatic disease before and after I-131 and to evaluate the influence of the new ATA guidelines in the management of DTC.

Methods: We retrospectively analyzed 140 patients showing distant metastases. All metastases were detected by whole-body scan after I-131 and confirmed by histology and/or other imaging modalities.

Results: In 26/140 patients metastases were detected before I-131, while in 114/140 were discovered after I-131. Comparing patients with metastases detected before and after I-131, no differences were demonstrated considering age, sex, histotype, tumor size, multifocality of cancer and metastatic localization. Metastatic DTC discovered before radioiodine had higher thyroglobulin and received a higher radioiodine total activity and number of treatments. Considering patients with distant metastases, according to the 2015 ATA guidelines, 38 patients would have been categorized as high risk, 22 as low risk and 80 as intermediate risk. Among intermediate-risk patients, only in 25 cases (31\%) I-131 treatment would have been appropriate according to 2015 ATA recommendations; in the remaining 56 cases (69\%), I-131 would not have been recommended.

Conclusions: According to the 2015 ATA guidelines, most of metastatic patients would not have been treated after surgery, with the risk of late diagnosis and delayed treatment.

\section{Introduction}

Differentiated thyroid cancer (DTC) is the most common endocrine malignancy accounting for 5\% of all cancers diagnosed each year in female population (1) and is considered a slowly growing disease with favorable prognosis. The 5-year survival rates for DTC are $99.8 \%$ for localized tumors, $97 \%$ for tumors with regional metastases and $57.3 \%$ for tumors with distant metastases (2). Metastatic DTC patients are a group with lower survival rate; they need an early and appropriate treatment to improve prognosis. Radioiodine therapy can be an effective treatment for metastatic patients and may contribute significantly to their life expectancy (3). In 2015, the American Thyroid Association (ATA) released the new version of the guidelines for the management www.eje-online.org

https://doi.org/10.1530/EJE-18-0253
C) 2018 European Society of Endocrinology Printed in Great Britain
Published by Bioscientifica Ltd. 
of patients with thyroid nodules and DTC (4), compared to the previous version (5); these guidelines show a huge effort to guide decision making with more than 100 recommendations. Despite this, many doubts and objections are arising about these guidelines $(6,7,8)$ and probably they should be a matter of debate and further discussions. One of the major critical issue is the indication for post-operative iodine-131 (I-131); 2015 ATA guidelines in 'Recommendation $51 \mathrm{~A}^{\prime}$ and 'Table 14' established that post surgery I-131 treatment should not be routinely performed in patients considered at low risk; this include patients with unifocal microcarcinoma and patients with larger tumor sizes up to $4 \mathrm{~cm}$. Instead, in patients with ATA high-risk, radioiodine therapy is routinely recommended. In patients with ATA low-tointermediate risk, that is the most commonly observed group, which includes patients with tumor size larger than $4 \mathrm{~cm}$ or with microscopic extrathyroidal extension (T3 according to AJCC classification), and patients with central neck and lateral neck compartment lymph nodes metastases (T1-T3, N1a-b), I-131 is not proposed as mandatory and should be considered only for patients with additional high-risk factors (including advanced age, morphological characteristics of nodes, number of nodes). Furthermore, in the description of the adverse features, there are many open questions without clear indications $(3,9)$; for example, there is no clear definition of advanced age. The term 'consider' is frequently adopted and it opens many clinical scenarios in patient management, making recommendations not univocal and susceptible to different interpretations. Controversial perspectives about I-131 indications could lead to a reduction of the number of patients eligible for radioiodine therapy, potentially missing metastatic disease. Our aim was to retrospectively analyze in a consecutive cohort of patients evaluated in our institute the prevalence of metastatic disease detected before and after I-131 and to evaluated what influence the new ATA guidelines would have had in the diagnostic work-up and/or treatment of metastatic patients.

\section{Subjects and methods}

We retrospectively screened 2516 patients who underwent I-131 for DTC after total or near total thyroidectomy from January 2008 until January 2017 using our institutional Radiology Information System. They were admitted to the Nuclear Medicine Department of our Institution for the ablation of thyroid remnant according European Association of Nuclear Medicine (EANM) guidelines
(10). Out of these 2516 patients, we identified 140 cases of metastatic DTC (91 female; 49 male; sex ratio F:M 1.9:1). All metastases were confirmed by histology when available and/or other imaging modalities (computed tomography, magnetic resonance imaging, positron emission tomography and ultrasonography).

The patients' age ranged from 16 to 82 years with a mean age of $57.4 \pm 16.2$; only three patients were pediatric (age less than 18 years) at the time of diagnosis. All patients had histopathological diagnosis of DTC: 58 classic variant of papillary carcinoma, 35 follicular variant of papillary carcinoma, 10 aggressive papillary variants (4 tall cells variant of papillary carcinoma and six poorly differentiated carcinoma), 35 follicular carcinoma and 2 Hurthle cell carcinoma. Tumor size was $3.1 \pm 2.2 \mathrm{~cm}$ (range: $0.15-7.5 \mathrm{~cm}$ ), multicentricity of neoplastic lesions was present in 59 cases (42\%) and extrathyroidal extension of primary carcinoma in 79 cases (56\%). One hundred and twenty-four patients underwent levothyroxine withdrawal for 40 days, replaced by levotriiodothyronine in the first 20 days and in 16 patients recombinant human thyrotropin (rhTSH-Thyrogen, Genzyme Corporation) was administered intramuscularly with a dose of $0.9 \mathrm{mg}$ over two consecutive days during treatment with levothyroxine, and radioiodine was administered the day after the second injection. All patients followed a low-iodine diet for 2 weeks and the serum thyrotropin (TSH) concentration was higher than $30 \mathrm{mIU} / \mathrm{L}$ before radioiodine administration. In patients without antithyroglobulin antibody (AbTg) interference, serum thyroglobulin ( $\mathrm{Tg}$ ) at the time of first radioiodine treatment was $303 \pm 329 \mathrm{ng} / \mathrm{mL}$ (range: 0.1-1001); AbTgs were positive in 30 patients (21\%).

All patients underwent whole-body scintigraphy followed by SPECT/CT scanning on the same day; the imaging was acquired 3-4 days after I-131 administration. Hybrid SPECT/CT scans from skull base to the lung bases were routinely obtained in all patients and additional SPECT/CT scans of other areas were performed depending on whole-body scintigraphy findings.

The administered activity of I-131 first treatments ranged from 1.1 to $7.4 \mathrm{GBq}$ (average: $3.2 \mathrm{GBq}$ ) and it was established according to the risk class based on the TNM staging of the American Joint Committee on Cancer/International Union against Cancer currently in use (11) and the status of the disease. Typically, 1.1 GBq were administered to low-risk patients, $1.85 \mathrm{GBq}$ to intermediate-risk patients and a high-dose $(3.7 \mathrm{GBq})$ to high-risk patients. The mean \pm standard deviation number of radioiodine therapies per patient was $4.3 \pm 2.7$ (range: 
1-11); the average cumulative I-131 activity administered per patient was $31.8 \pm 41.3 \mathrm{GBq}$ (range: $1.1-114 \mathrm{GBq}$ ). Baseline characteristics of all patients are summarized in Table 1 . The average follow-up time was $70 \pm 18$ months (range 9-118 months).

All patients gave their written informed consent; ethical statement that approves this study was not required due to its retrospective nature.

\section{Statistical analysis}

Statistical analysis was carried out using SPSS, version 23.0 for Windows (IBM). The descriptive analysis of categorical variables comprised the calculation of simple and relative frequencies. The numeric variables were described as mean, minimum and maximum. The statistical significance of the continuous variables was tested with a Student's $t$-test or Mann-Whitney's $U$ test and a $\chi^{2}$ test was performed for the categorical variables. A $P$ value of $\leq 0.05$ was considered as statistically significant.

Table 1 Baseline characteristics of 140 patients.

\begin{tabular}{|c|c|c|}
\hline & Average (range) & $\begin{array}{c}\text { Patients, } \\
\text { n (\%) }\end{array}$ \\
\hline Age & $57.4(16-82)$ & \\
\hline Male & & $49(65)$ \\
\hline Female & & $91(35)$ \\
\hline \multicolumn{3}{|l|}{ Histotype } \\
\hline Papillary & & $58(41)$ \\
\hline Follicular variant of papillary & & $35(25)$ \\
\hline Follicular & & $35(25)$ \\
\hline Aggressive variant & & $10(7)$ \\
\hline Hurtle cell & & $2(2)$ \\
\hline Tumor size $(\mathrm{cm})$ & $3.1(0.15-7.5)$ & \\
\hline \multicolumn{3}{|l|}{ Site of metastases } \\
\hline Lung & & $63(45)$ \\
\hline Bone & & $56(40)$ \\
\hline Lung + bone & & $16(11)$ \\
\hline Other & & $5(4)$ \\
\hline Multicentricity & & $59(42)$ \\
\hline $\begin{array}{l}\text { Tg at the time of ablation } \\
(\mathrm{ng} / \mathrm{mL})\end{array}$ & $303(0.1-1001)$ & \\
\hline AbTg positive patients & & $30(21)$ \\
\hline $\begin{array}{l}\text { Single RAl activities } \\
\text { administrated (GBq) }\end{array}$ & $3.2(1.1-7.4)$ & \\
\hline $\begin{array}{c}\text { Cumulative RAI activities } \\
\text { administrated (GBq) }\end{array}$ & $31.8(1.1-114)$ & \\
\hline $\mathrm{N}^{\circ}$ therapies & $4.3(1-13)$ & \\
\hline Follow-up time (months) & $70(9-118)$ & \\
\hline
\end{tabular}

GBq, gigabequerel; $\mathrm{N}^{\circ}$, number; $\mathrm{RAl}$, radioiodine; var, variant.

\section{Results}

Of the 2516 patients evaluated, 140 (5.6\%) showed distant metastases of DTC: 55 in the bone, 63 in the lung, 16 in bone and lung simultaneously and 6 in other localizations (Fig. 1). Histological confirmation was achieved in 68 patients, while in another 72 cases other imaging modalities confirmed the presence of metastases. Overall, 26 of $140(19 \%)$ metastases were detected before I-131, while 114 (81\%) were diagnosed after I-131. Considering the first group, metastases were localized in the bone in 14 patients, in the lung in 6 , in the bone and lung together in 3 , in the muscular system in 1 and in the bone and brain in 2 cases; in 15 cases, metastases were diagnosed because of complications or symptoms such as fractures, bone pain, cough, dyspnea, while in the remaining 11 cases, they were incidentally detected with other imaging techniques performed for other reasons. Thus, in these patients, the detection of metastases was the first step, which led to the diagnosis of DTC. All patients with metastases detected before I-131 were considered as ATA high-risk class of recurrence. Instead, in 114 patients with metastases discovered after I-131, 60 (53\%) metastases were recognized in the first whole-body scan after treatment, while the other 54 (47\%) were detected in the subsequent scintigraphies. Fortytwo of 114 were localized in the bone, 57 in the lung, 13 in both the lung and bone, 1 in the brain and 1 in the liver. Among patients with metastases detected after I-131, AbTgs were positive in 27 cases making Tg values unreliable (Fig. 2); in 14 cases with metastases detected at first whole-body scintigraphy and the remaining 13 in subsequent scintigraphies. Stimulated $\mathrm{Tg}$ values at first I-131 therapy was $129 \pm 174 \mathrm{ng} / \mathrm{mL}$ (range 0.1-1001) and was significantly lower compared to patients with metastases diagnosed before radioiodine therapy (438 ng/ $\mathrm{mL} ; P<0.001$; Table 2). In 29/87 (33\%), the stimulated Tg level at the time of I-131 was less than $10 \mathrm{ng} / \mathrm{mL}$, a value conventionally not considered suspicious for distant metastases. Among them, ten had distant metastases detected at the first whole-body scintigraphy after I-131 and 19 in the subsequent course of disease. In the remaining 58 patients, post-operative Tg value was less than $5 \mathrm{ng} / \mathrm{mL}$ in 32 cases (55\%) and less than $10 \mathrm{mg} / \mathrm{dL}$ in 39 (67\%). Thus, only in 19 cases post-operative Tg was higher than $10 \mathrm{ng} / \mathrm{mL}$, a value considered suspicious for the presence of distant metastases, and among them, ten were classified as high risk after surgery and before I- 131 .

Comparing patients with metastases detected before and after I-131, no differences were demonstrated 


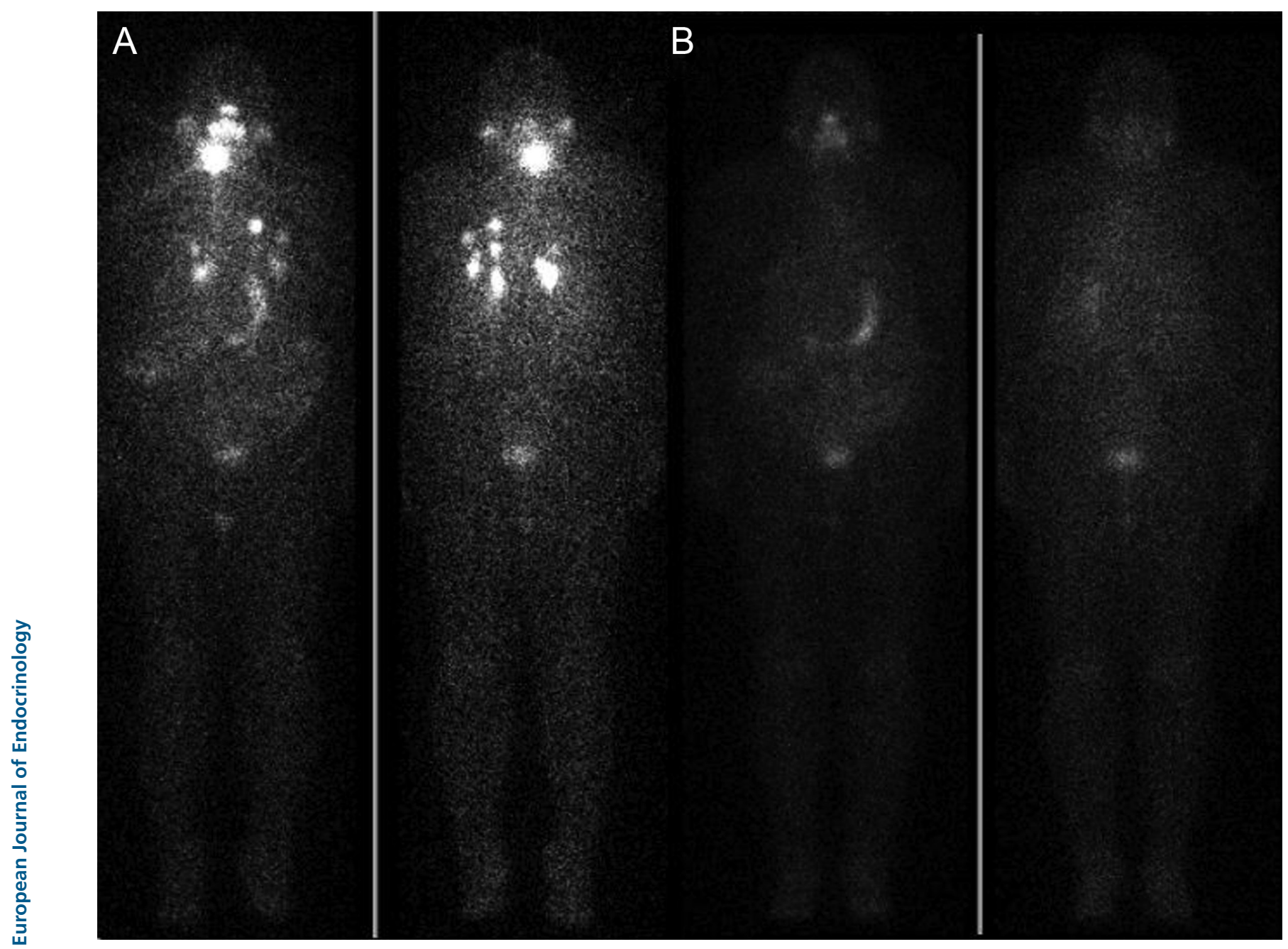

Figure 1

A representative case of a 64-year old woman with a conventional papillary carcinoma with thyroid capsule invasion and microscopic extrathyroidal extension and without cervical pathological nodes (pT3N0 according to AJCC 2010 classification, low-to-intermediate risk according to ATA 2015 guidelines). After thyroid hormone withdrawal, he received $3.7 \mathrm{GBq}$ of I131 for remnant ablation. The TSH level was $58 \mathrm{U} / \mathrm{L}$, serum $\mathrm{Tg} 7.8 \mathrm{ng} / \mathrm{mL}$ and serum $\mathrm{TgAb}<1 \mathrm{IU} / \mathrm{mL}$. I131 total body planar scintigraphy ( $A$, anterior and posterior views) showing intense uptake of tracer in the upper central area of the neck corresponding to residual thyroid tissue and several bilateral areas of thoracic focal uptakes due to metastatic lung lesions 1 year later, the total body planar scintigraphy ( $B$, anterior and posterior views) showing the disappearance of the previous uptakes with negative stimulated $\operatorname{Tg}(<1 \mathrm{ng} / \mathrm{mL})$.

considering age, sex, tumor size, histotype, multifocality of primary cancer, presence of AbTg and metastatic localization (Table 2). Metastatic DTC discovered before I-131 received a higher cumulative 131-I activity and number of treatments.

Considering all 140 patients, only 38 (27\%) were classified as high risk according to 2015 ATA guidelines after surgery and before I-131 (12 because of gross extrathyroidal extension and 26 because of distant metastases diagnosed before I-131); 22 (16\%) were classified as low risk, (tumor size less than $4 \mathrm{~cm}$ and without other pathological findings) and 80 (57\%) were classified in the in low-tointermediate risk class (17 patients with tumor size more than $4 \mathrm{~cm}, 23$ with microscopic extrathyroidal extension, 10 with the presence of nodal metastases in central neck compartment and 30 with metastatic lymph nodes in lateral neck compartment). Analyzing the 80 patients classified in ATA as low-to-intermediate risk, 16 presented adverse features potentially relevant for considering I-131 (in six cases due to the histological diagnosis of aggressive 

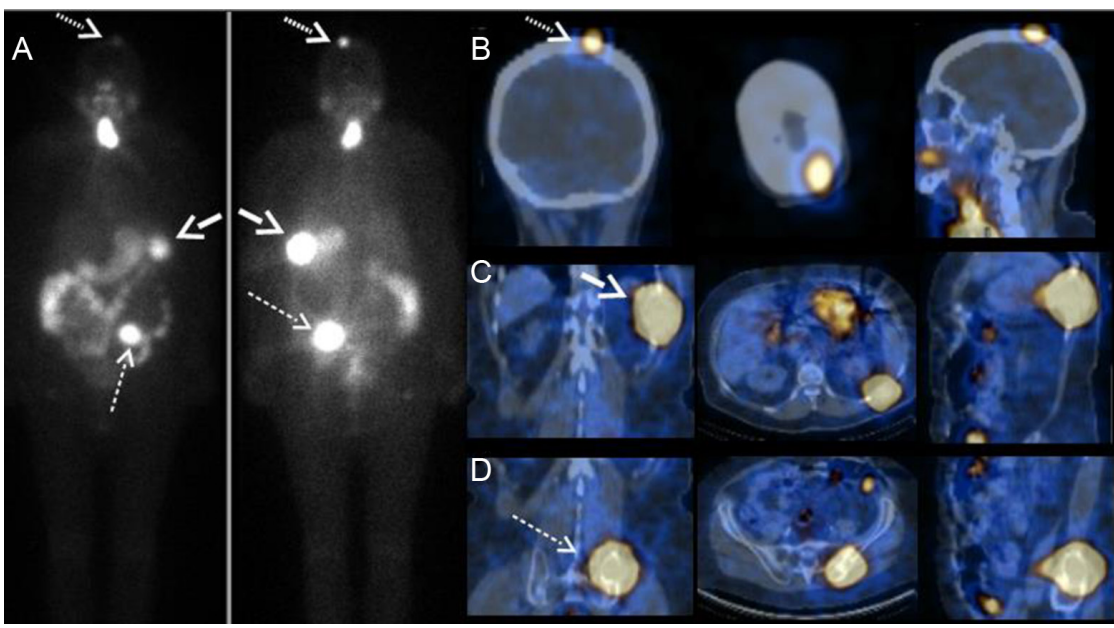

\section{Figure 2}

A representative case of 45-year old woman with a follicular carcinoma (pT1b according to AJCC 2010, low risk according to ATA 2015), positive AbTg $(75 \mathrm{IU} / \mathrm{mL})$ and undetectable $\mathrm{Tg}(<1 \mathrm{ng} / \mathrm{mL})$ after rh-TSH stimulation. 1131 total body planar scintigraphy (A) after $1.85 \mathrm{Gbq}$ of I131 demonstrating intense uptake in the neck corresponding to thyroidal remnant and three 1131 uptakes in the bone: skull (B dashed arrow, coronal, axial and sagittal images), a left rib (C thick arrow, coronal, axial and sagittal images) and the right sacroiliac joint ( $D$ thin dashed arrow, coronal, axial and sagittal images). A full color version of this figure is available at https://doi.org/10.1530/EJE-18-0253.

variant papillary carcinoma and in ten due to the presence of increasing number of large lymph nodes, more than $1 \mathrm{~cm}$, and/or clinical evidence of them) and nine had post-operative $\mathrm{Tg}$ higher than $10 \mathrm{ng} / \mathrm{mL}$. Thus, only in 25/80 (31\%) patients with low-to-intermediate risk, I-131 ablation would have been indicated according to 2015 ATA guidelines recommendations. In the remaining 55 (69\%), I-131 ablation of thyroid remnant would not have been recommended (Table 3). Among low-risk group, nobody had elevated post-operative Tg and/or adverse features.

Considering all 2516 patients analyzed between 2008 and 2017, 250 patients (10\%) were classified in ATA highrisk group, 1639 (66\%) in low-to-intermediate risk and $616(24 \%)$ in low risk.

\section{Discussion}

I-131 therapy of DTC was performed for the first time in 1943 (12); since then, the worth and efficacy of I-131 in DTC treatment has been proven in several landmark studies $(13,14)$, especially in carcinoma with diameter greater than $1 \mathrm{~cm}$ (15) and especially in DTC with distant metastases (3). The main aims of post-operative administration of I-131, also called 'ablation', were threefold: (1) to treat any remaining, unknown cancer tissue in the thyroid bed, lymph nodes or other locations; (2) to recognize and prevent recurrences and (3) to destroy any remaining healthy thyroidal cells contributing to make subsequent $\mathrm{Tg}$ determination during follow-up as a reliable tumor marker (16). Several authors have demonstrated the role of post- I-131 whole-body scan in the detection of occult distant metastases, mainly in bone and lung; distant metastases are the main cause of death and an early detection offers greater opportunities for a cure $(15,16,17,18,19)$. Moreover, in recent years, the introduction in clinical practice of single photon

Table 2 Comparison between clinical and pathological features in patients with metastases recognized before or after RAI.

\begin{tabular}{|c|c|c|c|}
\hline & $\begin{array}{c}\text { Metastases } \\
\text { before RAI } \\
(n=26) \\
\end{array}$ & $\begin{array}{c}\text { Metastases } \\
\text { after RAI } \\
(n=114) \\
\end{array}$ & $P$ value \\
\hline Sex F:M & $17: 9$ & $74: 40$ & 0.885 \\
\hline Age at diagnosis & 62.4 & 56 & 0.586 \\
\hline T tumor size $(\mathrm{cm})$ & 3 & 3.1 & 0.742 \\
\hline Multicentricity & 6 & 53 & 0.747 \\
\hline $\begin{array}{l}\text { Histotype: classic var } \\
\text { papillary }\end{array}$ & 6 & 52 & 0.612 \\
\hline Follicular var papillary & 6 & 29 & \\
\hline Follicular & 14 & 21 & \\
\hline Aggressive variants & 2 & 8 & \\
\hline Hurtle cell & 1 & 1 & \\
\hline Mean Tg at ablation (ng/mL) & 438 & 129 & $<0.001$ \\
\hline AbTg pos & 3 & 27 & 0.397 \\
\hline First RAI activity (GBq) & 3.6 & 3.1 & 0.08 \\
\hline $\begin{array}{l}\text { Cumulative RAI activities } \\
\text { (GBq) }\end{array}$ & 34.7 & 27.6 & 0.003 \\
\hline $\mathrm{N}^{\circ}$ therapies & 5.2 & 3.3 & 0.02 \\
\hline Metastases: bone & 14 & 42 & 0.111 \\
\hline Lung & 6 & 57 & 0.012 \\
\hline Lung + bone & 3 & 13 & 0.986 \\
\hline Other & 3 & 2 & 0.102 \\
\hline
\end{tabular}

Ab, antibodies; F, female; GBq, gigabequerel; $\mathrm{M}$, male; $\mathrm{N}^{\circ}$, number; pos, positive; RAl, radioiodine; $\mathrm{Tg}$, thyroglobulin. 
Table 3 Summary of patient's class risk features and indication to RAI following 2015 ATA guidelines.

\begin{tabular}{|c|c|c|c|c|c|}
\hline \multirow{3}{*}{$\frac{2015 \text { ATA risk class }}{\text { ATA high risk }(n=38)}$} & \multirow{3}{*}{$\begin{array}{l}\text { pTNM (AJCC 2010) } \\
\text { T4, any } \mathrm{N} \text {, any } \mathrm{M} \\
\mathrm{M1} \text {, any } \mathrm{T} \text {, any } \mathrm{N}\end{array}$} & \multirow{2}{*}{$\frac{\text { No. of patients }}{12}$} & \multirow{2}{*}{$\begin{array}{c}\begin{array}{c}\text { Adverse features } \\
\text { suggesting RAIT }\end{array} \\
\text { ne }\end{array}$} & \multicolumn{2}{|c|}{ Post surgical potential RAI indication } \\
\hline & & & & $12 / 12(100 \%)$ & $38 / 38(100 \%)$ \\
\hline & & 26 & ne & $26 / 26(100 \%)$ & \\
\hline \multirow[t]{4}{*}{ ATA low-to-intermediate risk $(n=80)$} & $\begin{array}{l}\text { T3, N0-x, M0-x for } \\
\text { tumor size }\end{array}$ & 17 & 2 & $2 / 17(12 \%)$ & $25 / 80(31 \%)$ \\
\hline & $\begin{array}{l}\text { T3, N0-x, M0-x for } \\
\text { extension }\end{array}$ & 23 & 4 & $4 / 23(17 \%)$ & \\
\hline & T1-3, N1a, M0-x & 10 & 7 & $7 / 10(70 \%)$ & \\
\hline & T1-3, N1b, M0-x & 30 & 12 & $12 / 30(40 \%)$ & \\
\hline \multirow[t]{2}{*}{ ATA low risk $(n=22)$} & T1a, N0-x, M0-x & 2 & 0 & $0 / 2(0 \%)$ & $0 / 22(0 \%)$ \\
\hline & T1b-2, N0-x, M0-x & 20 & 0 & $0 / 20(0 \%)$ & \\
\hline
\end{tabular}

ne, not evaluated; P, post surgical; RAIT, radioiodine therapy.

computerized tomography-computed tomography (SPECT-CT) acquisition has significantly improved the accuracy and detection rate (20).

In our analysis, we included all patients with distant metastases detected in our center, considering both patients with metastases detected before and after I-131. These two groups were similar seeing the main epidemiological and clinical features (age, sex, size, histotype, multifocality of thyroid cancer, presence of AbTg and site of metastases) as showed in Table 2. Instead, patients with distant metastases detected before radioiodine seemed to have a more aggressive behavior and needed a higher cumulative I-131 activity and a higher number of treatments.

Recent 2015 ATA guidelines have reduced the indication to I-131, suggesting a more conservative approach after surgery and, consequently, determining a significant reduction of candidates for I-131. In our paper, we have demonstrated that 102 patients after surgery would not have had a recommendation for I-131 because they were classified as ATA low and low-to-intermediate risk (22 and 80 respectively). Despite the fact that 25 patients showed the presence of additional adverse characteristics or higher post-operative Tg value (>10 ng/ $\mathrm{mL}$ ) potentially useful in 'considering' the I-131 option, in the remaining 77 I-131 might have been omitted. In these patients, the lack of I-131 could have affected their management, delaying both the diagnosis of metastatic disease and treatment and probably affecting the patient outcome. The high risk of downstaging DTC after surgery with consequent delay in therapeutic decision making should council caution in abandoning a long-established and successful clinical practice. The ATA 2015 guidelines (4) also emphasize the absence of specific studies about I-131 efficacy in the intermediate-risk group. In a recent systematic review, Lamartina et al. (21) reported conflicting results on the impact of I-131 treatment on disease recurrence, including in the paragraph dedicated to ATA intermediate-risk patients. The authors concluded that 'more research is needed to understand the therapeutic efficacy in various subgroups of patients in the ATA intermediate-risk category'. A surveillance without I-131 ablation is based on the assumption of an indolent course of DTC but several studies demonstrated adverse outcomes, due to regional or distant metastatic disease (22), in patients that delayed I-131. So far, the hypothesis that a less frequent use of I-131 could be clinically favorable and indicated is based on non-long-term follow-ups papers, often less than 10 years; longer follow-up periods (at least 10-15 years) are needed to assess reliably the effective role of I-131 therapy (23); in the meantime, in our opinion, I-131 remains a reasonable option, especially in the numerous situations where the literature is controversial (24). Avoiding I-131 ablation and subsequent wholebody scintigraphy can imply a systematic understaging of a non-negligible number of metastatic patients, with the only advantage of a mild reduction of the effective radiation dose exposure. It should be underlined that the administered activities are currently lower than those in the past, because $1.1 \mathrm{GBq}$ after thyroid remnant uptake stimulation by recombinant TSH was proven in multicenter trials $(25,26)$ to be effective in thyroid remnant ablation and comparable to higher activities. Some authors suggested performing a diagnostic pre-ablation I-123 or I-131 $(27,28,29,30)$ scan as an alternative to therapeutic 131I whole-body scintigraphy; however, 123I whole-body scan, independently of the tracer cost, can be sub-optimal due to the short half-life of this radiopharmaceutical, with the risk of missing metastatic lesions with late uptake and, conversely, a 131I scintigraphy performed with diagnostic activity (usually $185 \mathrm{MBq}$ ) could be not sensitive enough, especially for SPECT/CT imaging, in comparison with the therapeutic one, especially in case of isolated and 
small metastases $(31,32)$. The importance of an accurate initial staging should be strongly considered, taking into account an acceptable health detriment being adverse effects generally mild and transient especially in postoperative adjuvant I-131 $(33,34)$. Serum thyroglobulin determination has an important role in post-operative risk stratification, but post-operative $\mathrm{Tg}$ levels alone cannot be used as a milestone criterion to recommend for or against I-131. New recommendations include using post-operative Tg measurement (a few weeks after total thyroidectomy either TSH stimulated or not stimulated) as a tool to discriminate between high and low-risk patients and consequently for indication to adjuvant I-131 (35). Moreover, in some cases, $\mathrm{Tg}$ can be false negative in recurrent or metastatic DTC patients when there are thyroglobulin antibodies present (36). Different technical problems may involve $\mathrm{Tg}$ measurement and need to be carefully considered when using $\mathrm{Tg}$ as a marker for the presence of residual thyroid tissue. First, the possible interference from $\mathrm{TgAb}$ compromises the use of serum $\mathrm{Tg}$ as a tumor marker in immunometric methods (37); second, interferences by heterophilic antibodies, called 'high-dose hook effect', may lead to reporting inappropriately low serum $\operatorname{Tg}(37,38,39)$; third the variability between different $\mathrm{Tg}$ immunoassays should be considered $(29,40)$. As underlined in ATA 2015 guidelines (4), no precise Tg value cutoffs are established to define what is a complete thyroid removal to omit RAIT. Postoperative Tg value is strongly dependent on the type of determination (stimulated or nonstimulated), type of stimulation (rh-TSH vs withdrawal), the actual level of TSH stimulation and the volume of remnant thyroid tissue (9, $35,36)$. In our study, $25 \%$ of patients without pre-surgery known metastases had low stimulated $\mathrm{Tg}$ values (less than $10 \mathrm{ng} / \mathrm{mL}$ ), not suggesting the presence of distant metastases, confirming the poor value of post-operative $\mathrm{Tg}$ alone in the decision making for I-131. Moreover, also post-operative $\mathrm{Tg}$ value seems to be a poor tumoral marker because it may be frequently lower (41). Also in our study, only ten patients presented post-surgical $\mathrm{Tg}>10 \mathrm{ng} / \mathrm{mL}$ in the intermediate group and these $\mathrm{Tg}$ values led to radioiodine therapy. We agree that not all DTC patients who are treated with I-131 would really benefit from this therapy, but it is not objectively possible to identify these patients without evidence based criteria, which require large prospective studies with very long-term follow-ups.

This study has several limitations based on its retrospective analysis, the relative small sample of patients analyzed, partially due to the rarity of the metastatic disease in DTC patients, and the lack of histological confirm of every metastasis. In conclusion, our study demonstrates that distant metastases in DTC patients are mainly detected after I-131; the majority of these patients belong to the ATA system low-to-intermediate risk group. By following the 2015 ATA guidelines class risk definition and related indication to I-131, most of metastatic patients would not have been treated with I-131 after surgery, with the risk of missing the presence of metastases and consequent delayed diagnosis and treatment.

\section{Declaration of interest}

The authors declare that there is no conflict of interest that could be perceived as prejudicing the impartiality of this study.

\section{Funding}

This research did not receive any specific grant from any funding agency in the public, commercial or not-for-profit sectors.

\section{Acknowledgment}

The authors thank Prof. Maurizio Bestagno for the revision of manuscript.

\section{References}

1 Siegel RL, Miller KD \& Jemal A. Cancer statistics, 2018. CA: A Cancer Journal for Clinicians 201868 7-30.

2 Simard EP, Ward EM, Siegel R \& Jemal A. Cancers with increasing incidence trends in the United States: 1999 through 2008. CA: A Cancer Journal for Clinicians 201262 118-128. (https://doi. org/10.3322/caac.20141)

3 Verburg FA \& Luster M. Radioactive iodine (RAI) therapy for metastatic differentiated thyroid cancer. Best Practice and Research: Clinical Endocrinology and Metabolism. 201731 279-290. (https://doi. org/10.1016/j.beem.2017.04.010)

4 Haugen BR, Alexander EK, Bible KC, Doherty GM, Mandel SJ, Nikiforov YE, Pacini F, Randolph GW, Sawka AM, Schlumberger M et al. 2015 American Thyroid Association Management Guidelines for adult patients with thyroid nodules and differentiated thyroid cancer: the American Thyroid Association Guidelines task force on thyroid nodules and differentiated thyroid cancer. Thyroid 201626 1-133. (https://doi.org/10.1089/thy.2015.0020)

5 Cooper DS, Doherty GM, Haugen BR, Kloos RT, Lee SL, Mandel SJ, Mazzaferri EL, Mcliver B, Pacini F, Schlumberger M et al. Revised American Thyroid Association Management Guidelines for patients with thyroid nodules and differentiated thyroid cancer. Thyroid 2009 19 1167-1214. (https://doi.org/10.1089/thy.2009.0110)

6 Verburg FA, Aktolun C, Chiti A, Frangos S, Giovanella L, Hoffmann M, Iakovou I, Mihailovic J, Krause BJ, Langsteger W et al. Why the European Association of Nuclear Medicine has declined to endorse the 2015 American Thyroid Association management guidelines for adult patients with thyroid nodules and differentiated thyroid cancer. European Journal of Nuclear Medicine and Molecular Imaging 201643 1001-1005. (https://doi.org/10.1007/s00259-0163327-3)

7 Verburg FA, Luster M \& Giovanella L. Adjuvant post-operative I-131 therapy in differentiated thyroid carcinoma: are the 2015 ATA guidelines an exact science or a dark art? European Journal of Nuclear Medicine and Molecular Imaging 201744 183-184. (https://doi. org/10.1007/s00259-016-3526-y) 
8 Clerc J, Verburg FA, Avram AM, Giovanella L, Hindie E \& Taieb D. Radioiodine treatment after surgery for differentiated thyroid cancer: a reasonable option. European Journal of Nuclear Medicine and Molecular Imaging 201744 918-925. (https://doi.org/10.1007/s00259017-3654-z)

9 Frangos S, Iakovou IP, Marlowe RJ, Eftychiou N, Patsali L, Vanezi A, Savva A, Mpalaris V \& Giannoula EI. Acknowledging gray areas: 2015 vs. 2009 American Thyroid Association differentiated thyroid cancer guidelines on ablating putatively low-intermediate-risk patients. European Journal of Nuclear Medicine and Molecular Imaging 201744 185-189. (https://doi.org/10.1007/s00259-016-3495-1)

10 Luster M, Clarke SE, Dietlein M, Lassmann M, Lind P, Oyen WJ, Tennvall J, Bombardieri E \& European Association of Nuclear Medicine (EANM). Guidelines for radioiodine therapy of differentiated thyroid cancer. European Journal of Nuclear Medicine and Molecular Imaging 200835 1941-1959. (https://doi.org/10.1007/ s00259-008-0883-1)

11 Edge SB, Byrd DR, Compton CC, Fritz AG, Greene FL, Trotti A (eds.) AJCC Cancer Staging Manual. 7th ed. New York, NY: Springer, National Cancer Institute, 2010.

12 Seidlin SM, Marinelli LD \& Oshry E. Radioactive iodine therapy: effect on functioning metastases of adenocarcinoma of the thyroid. JAMA 1946132 838-847. (https://doi.org/10.1001/ jama.1946.02870490016004)

13 Hay ID, Thompson GB, Grant CS, Bergstralh EJ, Dvorak CE, Gorman CA, Maurer MS, Mciver B, Mullan BP, Oberg AL et al. Papillary thyroid carcinoma managed at the Mayo Clinic during six decades (1940-1999): temporal trends in initial therapy and longterm outcome in 2444 consecutively treated patients. World Journal of Surgery 200226 879-885. (https://doi.org/10.1007/s00268-0026612-1)

14 Verburg FA, Mader U, Tanase K, Thies ED, Diessl S, Buck AK, Luster M, Reiners C. Life expectancy is reduced in differentiated thyroid cancer patients $\geq 45$ years old with extensive local tumor invasion, lateral lymph node, or distant metastases at diagnosis and normal in all other DTC patients. Journal of Clinical Endocrinology and Metabolism 201398 172-180. (https://doi.org/10.1210/jc.2012-2458)

15 Durante C, Haddy N, Baudin E, Leboulleux S, Hartl D, Travagli JP, Caillou B, Ricard M, Lumbroso JD, De Vathaire F et al. Long-term outcome of 444 patients with distant metastases from papillary and follicular thyroid carcinoma: benefits and limits of radioiodine therapy. Journal of Clinical Endocrinology and Metabolism 200691 2892-2899. (https://doi.org/10.1210/jc.2005-2838)

16 Hindie E, Melliere D, Lange F, Hallaj I, de Labriolle-Vaylet C, Jeanguillaume C, Lange J, Perlemuter L \& Askienazy S. Functioning pulmonary metastases of thyroid cancer: does radioiodine influence the prognosis? European Journal of Nuclear Medicine and Molecular Imaging 200330 974-981. (https://doi.org/10.1007/s00259-0031174-5)

17 Hindie E, Zanotti-Fregonara P, Keller I, Duron F, Devaux JY, CalzadaNocaudie M, Sarfati E, Moretti JL, Bouchard P \& Toubert ME. Bone metastases of differentiated thyroid cancer: impact of early 131I-based detection on outcome. Endocrine-Related Cancer 200714 799-807. (https://doi.org/10.1677/ERC-07-0120)

18 Casara D, Rubello D, Saladini G, Masarotto G, Favero A, Girelli ME $\&$ Busnardo B. Different features of pulmonary metastases in differentiated thyroid cancer: natural history and multivariate statistical analysis of prognostic variables. Journal of Nuclear Medicine 199334 1626-1631.

19 Orita Y, Sugitani I, Matsuura M, Ushijima M, Tsukahara K, Fujimoto Y \& Kawabata K. Prognostic factors and the therapeutic strategy for patients with bone metastasis from differentiated thyroid carcinoma. Surgery 2010147 424-431. (https://doi.org/10.1016/j. surg.2009.10.009)

20 Zilioli V, Peli A, Panarotto MB, Magri G, Alkraished A, Wiefels C, Rodella C \& Giubbini R. Differentiated thyroid carcinoma: incremental diagnostic value of 131I SPECT/CT over planar whole body scan after radioiodine therapy. Endocrine 201756 551-559. (https://doi.org/10.1007/s12020-016-1086-3)

21 Lamartina L, Durante C, Filetti S \& Cooper DS. Low-risk differentiated thyroid cancer and radioiodine remnant ablation: a systematic review of the literature. Journal of Clinical Endocrinology and Metabolism 2015100 1748-1761. (https://doi.org/10.1210/ jc.2014-3882)

22 Higashi T, Nishii R, Yamada S, Nakamoto Y, Ishizu K, Kawase S, Togashi K, Itasaka S, Hiraoka M, Misaki T et al. Delayed initial radioactive iodine therapy resulted in poor survival in patients with metastatic differentiated thyroid carcinoma: a retrospective statistical analysis of 198 cases. Journal of Nuclear Medicine 201152 683-689. (https://doi.org/10.2967/jnumed.110.081059)

23 Verburg FA, Mader U, Reiners C \& Hanscheid H. Long-term survival in differentiated thyroid cancer is worse after low-activity initial post-surgical 131I therapy in both high- and low-risk patients. Journal of Clinical Endocrinology and Metabolism 201499 4487-4496 (https:// doi.org/10.1210/jc.2014-1631)

24 Melliere D, Hindie E, Becquemin JP, Desgranges P, Allaire E \& Geachan E. Differentiated thyroid carcinoma-how to improve the long-term results? Twenty-five-year outcomes of 850 patients. Bulletin de l'Academie Nationale de Medecine 2006190 89-106.

25 Schlumberger M, Catargi B, Borget I, Deandreis D, Zerdoud S, Bridji B, Bardet S, Leenhardt L, Bastie D, Schavrtz C et al. Tumeurs de la Thyroïde Refractaires Network for the essai stimulation ablation equivalence trial. Strategies of radioiodine ablation in patients with low-risk thyroid cancer. New England Journal of Medicine 2012366 1663-1673. (https://doi.org/10.1056/NEJMoa1108586)

26 Mallick U, Harmer C, Yap B, Wadsley J, Clarke S, Moss L, Nicol A, Clark PM, Farnell K, McCready R et al. Ablation with low-dose radioiodine and thyrotropin alfa in thyroid cancer. New England Journal of Medicine 2012366 1674-1685. (https://doi.org/10.1056/ NEJMoa1109589)

27 Avram AM, Esfandiari NH \& Wong KK. Preablation 131-I scans with SPECT/CT contribute to thyroid cancer risk stratification and 131-I therapy planning. Journal of Clinical Endocrinology and Metabolism 2015100 1895-1902. (https://doi.org/10.1210/jc.2014-4043)

28 Avram AM, Fig LM, Frey KA, Gross MD \& Wong KK. Preablation 131-I scans with SPECT/CT in postoperative thyroid cancer patients: what is the impact on staging? Journal of Clinical Endocrinology and Metabolism 201398 1163-1171. (https://doi.org/10.1210/jc.20123630)

29 Chen MK, Yasrebi M, Samii J, Staib LH, Doddamane I \& Cheng DW. The utility of I-123 pretherapy scan in I-131 radioiodine therapy for thyroid cancer. Thyroid 201222 304-309. (https://doi.org/10.1089/ thy.2011.0203)

30 Silberstein EB. Comparison of outcomes after (123)I versus (131) I pre-ablation imaging before radioiodine ablation in differentiated thyroid carcinoma. Journal of Nuclear Medicine 200748 1043-1046. (https://doi.org/10.2967/jnumed.107.040311)

31 Sarkar SD, Kalapparambath TP \& Palestro CJ. Comparison of I123 and I131 for whole body imaging in thyroid cancer. Journal of Nuclear Medicine 200243 632-634.

32 Iwano S, Kato K, Nikashi T, Ito S, Tachi Y \& Nahanawa S. Comparison of I-123 diagnostic and I-131 post-treatment scans for detecting residual thyroid tissue and metastases of differentiated thyroid cancer. Annals of Nuclear Medicine 200923 777-782. (https://doi. org/10.1007/s12149-009-0303-z)

33 Fard-Esfahania A, Emami-Ardekania A, Fallahia B, Fard-Esfahanib P Beikia D, Hassanzadeh-Rada A \& Eftekhari M. Adverse effects of radioactive iodine-131 treatment for differentiated thyroid carcinoma. Nuclear Medicine Communications 201435 808-817.

34 Hyer SL, Newbold K \& Harmer CL. Early and late toxicity of radioiodine therapy: detection and management. Endocrine Practice 201016 1064-1070. (https://doi.org/10.4158/EP10170.RA) 
35 Herk MH, Francis P, Topliss DJ, Bailey M \& Kalff V. Incidence and implications of negative serum thyroglobulin but positive I-131 whole-body scans in patients with well-differentiated thyroid cancer prepared with rhTSH or thyroid hormone withdrawal. Clinical Endocrinology 201276 734-740. (https://doi.org/10.1111/j.13652265.2011.04278.x)

36 Park EK, Chung JK, Lim IH, Park DJ, Lee DS, Lee MC \& Cho BY. Recurrent/metastatic thyroid carcinomas false negative for serum thyroglobulin but positive by post therapy I- 131 whole body scans. European Journal of Nuclear Medicine and Molecular Imaging 200936 172-179. (https://doi.org/10.1007/s00259-008-0912-0)

37 Spencer C \& Fatemi S. Thyroglobulin antibody (TgAb) methodsstrengths, pitfalls and clinical utility for monitoring TgAb-positive patients with differentiated thyroid cancer. Best Practice and Research: Clinical Endocrinology and Metabolism 201327 701-712. (https://doi. org/10.1016/j.beem.2013.07.003)

38 Giovanella L, Clark PM, Chiovato L, Duntas L, Elisei R, FeldtRasmussen U, Leenhardt L, Luster M, Schalin-Jantti C, Schott M et al.
Thyroglobulin measurement using highly sensitive assays in patients with differentiated thyroid cancer: a clinical position paper. European Journal of Endocrinology 2014171 R33-R46. (https://doi.org/10.1530/ EJE-14-0148)

39 Giovanella L, Suriano S, Ceriani L \& Verburg FA. Undetectable thyroglobulin in patients with differentiated thyroid carcinoma and residual radioiodine uptake on a postablation whole-body scan. Clinical Nuclear Medicine 201136 109-112. (https://doi.org/10.1097/ RLU.0b013e318203bb84)

40 Giovanella L, Imperiali M, Verburg FA \& Trimboli P. Early post treatment risk stratification on differentiated thyroid cancer: comparison of three high-sensitive $\mathrm{Tg}$ assys. European Journal of Endocrinology 2018178 77-84. (https://doi.org/10.1530/EJE-17-0663)

41 Campenni A, Giovanella L, Pignata SA, Vento A, Alibrandi A, Sturiale L, Laudicella R, Comis AD, Filice R et al. Undetectable or low $(<1 \mathrm{ng} / \mathrm{mL})$ postsurgical thyroglobulin value do not rule out metastases in early stage differentiated thyroid cancer patients. Oncotarget 20189 17491-17500.

Received 28 March 2018

Revised version received 9 May 2018

Accepted 7 June 2018 